\title{
Assef Khalili
}

Department of Basic Sciences, Faculty of Paramedicine

Tabriz University of Medical Sciences, Iran

khalilias@tbzmed.ac.ir

\section{Simin Sattarpour*}

Department of Basic Sciences, Faculty of Paramedicine

Tabriz University of Medical Sciences, Iran

sattarpours@tbzmed.ac.ir

\section{THE IMPACT OF EDITING ON METADISCOURSE IN DENTISTRY RESEARCH ARTICLES WRITTEN BY NON-NATIVE ENGLISH SPEAKERS}

\section{Abstract}

Non-native English speaking (NNES) authors are increasingly being pressured to get published in accredited international journals. Despite the important responsibility that editors shoulder in deciding the ultimate fate of academic papers, few studies have systematically explored the effects editing might have on specific writing features, whether linguistically or stylistically. That is what we set out to do in the present research. Twenty research articles in the field of dentistry written by NNES authors were randomly selected, and the original versions were contrasted with their edited versions, trying to establish what shortcomings the papers had in terms of Metadiscourse (MD) elements and how far the editing process had succeeded in compensating for those drawbacks. Hyland's (1998) account of MD in academic texts was utilized as our basis for comparison. The results revealed that NNES authors had paid scarce attention to proper management of MD elements in their manuscripts for effective communication of the propositional content, and that the editing process seemed to have changed little in this regard. It is believed that the findings of this study have some implications for ESP and EAP teachers, especially in academic paper writing classes, as well as for editors.

\section{Key words}

non-native English speaking authors, metadiscourse, editing, editors, academic paper.

\footnotetext{
* Corresponding address: Simin Sattarpour, Department of Basic Sciences, Faculty of Paramedicine, Tabriz University of Medical Sciences, 29 ${ }^{\text {th }}$ Bahman Boulevard, Daneshgah St., Tabriz, Iran.
} 


\section{INTRODUCTION}

English is recognized as the primary means of research communication worldwide, and authors around the globe find themselves compelled to produce papers in English if they are to get published in accredited journals. In such a 'publish or perish' atmosphere, non-native authors of English are particularly disadvantaged because poorly written articles have been found to be strongly correlated with high paper rejection rate (Coates, Sturgeon, Bohannan, \& Pasini, 2002; Ehara \& Takahashi, 2007), and linguistic factors have been reported to constitute an additional obstacle to negotiate on the path to academic publication (Ferguson, 2007). Of course some find the existing global inequities in academic publishing more economically than linguistically founded (Hultgren, 2019), or blame such inequities on regional constraints (e.g. low investment in research, suboptimal research training, limited education in how to write scientific articles, etc.) rather than the authors' first language (Hyland, 2016).

Whatever the case may be, non-native English speaking (NNES) authors, in practice, have been increasingly impelled to have their manuscripts reviewed by native English speaking (NES) authors (as required, at times, by the academic journal itself) (Li \& Flowerdew, 2007; Willey \& Tanimoto, 2013) or a particular type of language or academic expert, referred to by different terms, depending on the kind of services they provide in improving the quality of the paper: authors' editors (Burrough-Boenisch, 2003; Flowerdew \& Wang, 2016), article shapers (Burrough-Boenisch, 2003; Li \& Flowerdew, 2007), convenience editors (Willey \& Tanimoto, 2012, 2013, 2015), literacy brokers (Lillis \& Curry, 2006, 2010), and text mediators (Luo \& Hyland, 2016, 2017). On the other hand, getting professional editing services have been reported to be quite expensive (Salager-Meyer, 2008) while working with other personal editors can be really time-consuming, with even the accuracy of the finished work being unreliable (Huang, 2010).

Given the obviously important role of editing process, it has been explored from different perspectives. Certain researchers (Lillis \& Curry, 2010; Luo \& Hyland, 2016, 2017; Shaw \& Voss, 2017; Willey \& Tanimoto, 2012, 2013, 2015) have essentially focused on the editor types and their different approaches and strategies. Dividing the editors into specialist and non-specialist (English experts) categories, Lillis and Curry (2010) along with Willey and Tanimoto (2012, 2013) drew the conclusion that the specialists performed more effectively than their nonspecialist counterparts who seemed to be facing a lot of uncertainties, some of which they had no choice but to ignore. In contrast, Luo and Hyland $(2016,2017)$ underscored the contribution of non-specialists in the editing process, listing the benefits that authors could obtain through working with them.

There is yet another group of researchers who have focused on different revisions by editors (e.g. Bisaillon, 2007; Flowerdew \& Wang, 2016; Koyalan \& Mumford, 2011). For instance, Bisaillon (2007) identified three levels of detection, namely certitude, uncertainty and ignorance, with the editors either leaving a note 
to the authors or ignoring the problematic segments altogether. Koyalan and Mumford (2011) recounted five major types of 'register modification' which editors may resort to in the editing process, including nominalization, subordination, nonfinite clauses, prepositional phrases and noun premodification. Studying the types of changes a paper might undergo in the revision process, Flowerdew and Wang (2016) identified four types of revision, including substitution, correction, addition, and deletion at four different lexico-grammatical levels. They remarked that with the exception of correction and substitution, the remainder of the categories involved more substantial modifications that could change the text meaning and had to be negotiated between the author and the editor.

In a different study, Burgess and Lillis (2013) described different types of author-editor relationships, investigating a variety of responsibilities and expectations and how they are met. They thought to establish which type of relationship might yield the best possible results, concluding that editing is a multifaceted undertaking. "It [editing] is a spectrum of overlapping roles and practices that often change over time and vary according to specific contexts and relationships" (Burgess \& Lillis, 2013: 13).

However, to the best of our knowledge, editing has never been investigated systematically with regard to the use of important linguistic resources known to influence the organizational and interactive aspects of writing - the use of Metadiscourse (MD) elements. We aimed at focusing on the use of MD as a particular pragmatic feature of language to judge the effectiveness of editing. Our focus on the use of MD was prompted by the indispensable role MD could play in academic communication, and we had to limit ourselves to MD alone for practical feasibility of our analysis.

After all, academic writing is no longer viewed as discourse of truth, with its validity and efficacy hinging on impeccable reasoning and impersonal empiricism. Rather, academic papers are now viewed as conversations between members of academic communities (Hyland \& Jiang, 2016), where authors have to establish a shared community context through the right rhetorical choices providing for interpersonal negotiations and balancing their claims about the significance and originality of their work (Hyland, 2005). This is where judicious use of MD comes in, providing for authorial intrusions and text organization to help readers assess and react to the propositional content (Hyland \& Jiang, 2016).

Metadiscourse is indisputably among the resources which can play a significant role in the 'communicative content' of discourse, embodying the notion that "language not only refers to the world, concerned with exchanging information of various kinds, but also to itself: with material which helps readers to organize, interpret and evaluate what is being said" (Hyland, 2017: 17). We also fully subscribe to the view advocated by Hyland (2005: 33), who regards texts as "communicative acts, not lists of propositions" and emphasizes the central role of the MD devices in the expression of meaning of a text which depends on the integration of its component elements, both propositional and metadiscoursal. 
Based on various conceptualizations of the term, different scholars have posited their own models and taxonomies of MD. Following Vande Kopple (1985), credited with the first systematic treatment of MD, the majority of other theorists have also divided MD into textual and interpersonal categories (e.g. Crismore, Markkanen, \& Steffensen, 1993; Dahl, 2004; Mauranen, 1993). Besides this major similarity, some have extended the initial list to include wider categories, and others have manipulated the categories in their own ways, adding, separating, conflating or reorganizing the previous ones to fit the list to the particular view point they hold on the subject. However, rather against the mainstream studies of MD, Hyland (1998, 2004, 2005) suggested that the distinction between textual/interpersonal MD is misleading because it overlooks the meaning overlap between them. Hyland and Tse (2004) also asserted "all meta discourse is interpersonal in that it takes account of the readers' knowledge, textual experiences, processing needs and that it provides the author with an armory of rhetorical appeals to achieve this" (2004: 161).

In short, adopting an essentially interpersonal focus in his revised model, Hyland (2004) dropped textual MD from his model, and instead further divided the interpersonal MD into finer aspects: Interactive and Interactional categories, calling these two categories two sides of the same coin (2004: 17). The Interactive MD addresses ways of organizing discourse, rather than experience, and reveals the extent to which the text is constructed with the readers' needs in mind, thus providing for reader-friendliness of the text. The Interactional MD, on the other hand, concerns how authors engage in interaction and make their presence felt by projecting themselves onto the message and commenting on it, allowing the readers to respond to the unfolding text. Metadiscourse here is essentially evaluative and engaging, expressing solidarity, anticipating objections and responding to an imagined dialogue with others.

Irrespective of the various taxonomies, as a highly influential and productive concept in the study of spoken and written texts, MD still remains an intriguing topic which has been instigating a variety of research studies around the globe (Hyland, 2017). The bulk of research in this field comprises contrastive studies investigating the use of MD in a particular genre in two languages (one being almost always English). Thus Marandi (2003), for instance, investigated the impact of language/culture on the use of two types of MD markers, textual and interpersonal, in the introduction and discussion sections of the Master's theses of three groups: native Iranian speakers of Persian, non-native Iranian speakers of English, and native British speakers of English. The findings showed that, on the whole, textual MD was used significantly more in introductions than in discussions. Moreover, NES authors used significantly more hedging and less attributors than native speakers of Persian and more personal markers than NNES ones. Similarly, Pérez-Llantada (2010) analyzed text-oriented and participant-oriented MD crossculturally and cross-linguistically in introduction and discussion sections of English RAs written by English and Spanish authors as well as Spanish RAs written 
by Spanish authors. She found higher frequency of text-oriented MD in introductions, but roughly equal distribution of text- and participant-oriented MD in discussions. She also concluded that the authors publishing RAs in English used more MD elements and wrote reader-friendlier texts in comparison with Spanish authors publishing RAs in their native language.

There have also been other studies exploring particular features of MD, for instance the contribution of MD elements for the identification of generic moves (Khedri, Heng, \& Ebrahimi, 2013), author-reader interaction as evidenced by the use of Engagement Markers in the span of 50 years (Hyland \& Jiang, 2016), the changes in the level of formality and rhetorical conventions (Hyland \& Jiang, 2017), and the changes in the use of MD in research articles across different disciplines (Salas, 2015). However, the use of MD by NNES authors, who are the target group in many ESP programs, has not been studied sufficiently. Two of the few examples might be Blagojević (2004) and Khalili and Aslanabadi (2014), who contrasted MD in NNES authors' RAs, Norwegian and Iranian respectively, with that of NES in an attempt to address the nature of differences in the two data sets.

However, there are practically no studies exploring how editing might affect the use of MD in manuscripts produced by NNES, and whether or not the changes brought about by the editing process actually enhance the quality of a manuscript with regard to the use of MD as determined by NES standards (see Hyland, 1998).

\section{THE CURRENT STUDY}

In the present study, having contrasted the unedited manuscripts with their edited published versions, we attempted to benchmark the editors' work against the use of MD markers, trying to establish if the editing process has managed to push the NNES manuscripts towards the NES norms as far as the use of MD markers is concerned. More specifically, the following research questions are addressed in the current study:

1. Does editing process make any changes in the frequency of MD use, in general, in the dentistry RAs written by Iranian NNES authors?

2. If yes, what are the changes like in terms of particular MD elements in different sections of an academic paper?

Accordingly, we first bring forward the practice of editing and its crucial role in academic publishing and then explicate the significance of MD in the genre of academic texts. We also briefly review the existing literature on the use of MD in academic papers as well as the works related to editing research articles (RAs). Subsequently, in the methodology section, we describe the corpus utilized in the study, the participants who edited the RAs, and also the model used for coding the 
data. Moreover, a detailed account of the processes of data analysis is provided in this part. In the next section of the paper, the results are presented in tables and figures alongside thorough explanations. Finally, we present the conclusions drawn from the results and discuss the implications for the individuals involved in the process of RA writing and publishing.

\section{METHODOLOGY}

\subsection{The corpus}

Our corpus consisted of 20 articles from the Journal of Dental Research, Dental Clinics, and Dental Prospects published by the Faculty of Dentistry, Tabriz University of Medical Sciences, along with their unedited versions, which the editor in chief of the journal agreed to share with us after he was ensured about our observing the ethical concerns regarding the anonymity of the authors. Thus, our corpus actually consisted of 40 articles all of which were analyzed in terms of the MD devices used by NNES authors, and how their use and frequency were affected in the editing process, as evidenced in their final format in the journal. The selection of the papers was random, and the primary criterion for inclusion in the corpus was the papers having the standard format of Introduction, Method, Results, and Discussion.

There were three editors, as reported by the journal's editor in chief, who were in-house proof readers, working part time for the journal. All three editors were dentistry graduates, and highly proficient in English, with 5-12 years' experience in editing as well as the experience of teaching English in renowned language institutes. The editors' main responsibility was to format and iron out their lexico-grammatical problems of the papers which had already been approved content wise, and accepted with minor revisions. The editors were not and, according to the editor in chief, they did not need to be, in direct touch with the home authors; however, they occasionally had to contact authors from other countries through E-mail correspondence, asking for clarification of certain confusing segments.

\subsection{Model for the analysis of meta-discourse elements}

Out of the major MD taxonomies developed for MD, we adopted Hyland's (2004) revised taxonomy as our analytical model. Hyland proposes that all MD is interpersonal and posits two aspects for it: the Interactive MD Markers and Interactional MD Markers (Table 1). The Interactive MD elements are assumed to make a text more reader friendly while the interpersonal MD is essentially 
concerned with the authors making themselves visible by expressing their views, doubts, evaluation, judgments, etc. In other words, it is the author's expression of a textual 'voice', or community-recognized personality.

\begin{tabular}{|c|c|c|}
\hline & FUNCTION & EXAMPLES \\
\hline Interactive resources & $\begin{array}{l}\text { Help to guide reader through the } \\
\text { text }\end{array}$ & \\
\hline Transitions & $\begin{array}{l}\text { Express semantic relation } \\
\text { between main clauses }\end{array}$ & In addition/but/thus/and \\
\hline Frame Markers & $\begin{array}{l}\text { Refer to discourse acts, } \\
\text { sequence, or text stages }\end{array}$ & $\begin{array}{l}\text { Finally/to conclude/my purpose here is } \\
\text { to }\end{array}$ \\
\hline Endophoric Markers & $\begin{array}{l}\text { Refer to information in other } \\
\text { parts of the text }\end{array}$ & Noted above/see Fig./ in section 2 \\
\hline Evidentials & $\begin{array}{l}\text { Refer to source of information } \\
\text { from other texts }\end{array}$ & According to $\mathrm{X} /(\mathrm{Y}, 1990) / \mathrm{Z}$ states \\
\hline Code glosses & $\begin{array}{l}\text { Help readers grasp functions } \\
\text { of ideational material }\end{array}$ & Namely/e.g./such as/in other words \\
\hline $\begin{array}{l}\text { Interactional } \\
\text { resources }\end{array}$ & Involve the reader in the argument & \\
\hline Hedges & $\begin{array}{l}\text { Withhold author's full commitment } \\
\text { to proposition }\end{array}$ & might/perhaps/possible/about \\
\hline Boosters & $\begin{array}{l}\text { Emphasize force or author's } \\
\text { certainty in proposition }\end{array}$ & in fact/definitely/it is clear that \\
\hline Attitude Markers & $\begin{array}{l}\text { Express author's attitude } \\
\text { to proposition }\end{array}$ & Unfortunately/I agree/ surprisingly \\
\hline Engagement Markers & $\begin{array}{l}\text { Explicitly refer to or build } \\
\text { relationship with reader }\end{array}$ & Consider/note that/you can see that \\
\hline Self-mentions & Explicit reference to author(s) & I/we/my/our \\
\hline
\end{tabular}

Table 1. A model of metadiscourse in academic texts (adapted from Hyland, 2005)

\subsection{Data coding and analysis}

Although Hyland's (2005) model is our preferred one, as he himself admits it, the model is far from comprehensive in representing the whole array of MD elements encountered in academic texts. Obviously, our goal was not to try to enhance the comprehensiveness of the model by adding categories; however, there were a few occasions when we had to make slight modifications or adjustments to the existing model on the basis of Hyland's three main principles: 1) MD is distinct from propositional content, 2) all MD is interpersonal, and 3) MD refers to relations internal to discourse not external ones. The only reason for such modifications was to be able to accommodate our data with regard to the use of MD elements as 
comprehensively as possible. Data coding processes, involving some modifications to Hyland's model, are presented below.

1. Projecting clauses seem to provide an orientation to guide the reader, or a frame in which the main message can be expressed, but they have not been allocated to a particular category. Thus, Projecting clauses are treated as MD elements within the existing model, differentiated on the basis of their headwords.

a. when the authors' presence was indicated in the projecting clauses, e.g. our results revealed that, they were considered an instance of Self-Mentions.

b. when another author's name was quoted in the initial position of a projecting clause it was also regarded as another element of Interactional resources. This is not accounted for in Hyland's model, but it is considered a domain of discourse participant in Gosden's (1993) model. We are just suggesting this item as a supplement to the Interactional category of Self-mentions, and will refer to it as supplement/secondary Self-mentions.

c. when the head word of a Projecting clause referred to macro discourse elements like most studies have reported, or this model shows that, it was counted as either Evidentials or Endophoric Markers (as explained below).

d. finally, when the Projecting clauses included neither Evidentials nor Endophoric Markers mentioned above (e.g. there are speculations that), these clauses were simply counted as instances of Frame Marker Clauses, because of their function which is to contextualize the message about to be stated.

2. Expressions like the present research or in this article etc. are not accounted for in Hyland's model, even though they are clearly performing a meta-discoursal function. Thus, trying to incorporate such expressions into our analysis and to avoid further complications, we simply put these expressions into the existing most similar categories. As Endophoric Markers are used to refer to other parts of the text, we suggest that these elements be considered Endophoric Markers.

3. By the same token, Evidentials are said to refer to the source of information from other texts, and thus when the source of the information was not clearly specified (e.g. previous works) we still encoded these items as Evidentials.

4. Parentheses were also included in our analysis. We put them into the category of Code Glosses as their dominant function is often to provide details on or to facilitate the comprehension of ideational material, but differentiated them as Code Glosses Parentheses.

5. Expressions like in this situation or in this line of reasoning are clearly performing MD roles by naming or renaming a particular process or factor to provide guidance for the reader. They were coded as Frame Markers. 
Although we endeavored to be as objective as possible, there were occasions when we had to resort to subjective criteria. For example, the word previously would seem to be an adverb indicating a semantic relationship, yet the way it was used in article 12 actually referred to previous research or previous scholars, and thus was categorized as such. Of course, given the multifunctionality of linguistic elements in general, and the fact that MD elements have little lexical content (Hyland \& Jiang, 2016), it should come as no surprise to find that MD elements are highly context dependent, which makes apriori specification and classification of MD elements practically impossible.

Having reviewed the abovementioned principles together, the two authors randomly selected 4 RAs, 2 each, and worked independently in the process of assigning MD devices to their respective categories. Due to several instances of indeterminacies and disagreements as to how to categorize certain linguistic elements as well as the practical insufficiency of the model on a couple of occasions, certain categories were improvised to preserve the descriptive power of the data after receiving Hyland's approval through personal E-mail correspondence [Nov 6th, 2015] on the MD function of the improvised sub-categories.

Finally, having reached a complete agreement and cross-checked instances of indeterminacy, the researchers set about analyzing the remaining 16 articles. All articles were analyzed by both researchers independently, and the inter-rater reliability coefficient of 0.87 was obtained in terms of total number of MD elements in articles, which was considered acceptable. The identification and allocation of MD elements were initially completed in the unedited/original versions of the RAs, and then compared with the edited or final form of the RAs.

\section{RESULTS AND DISCUSSION}

Unlike the previous works providing only holistic descriptions of the MD use (e.g. Hyland, 1998, 2017), our data were also tabulated for all four sections of RAs separately. All MD elements used in the unedited drafts were recorded, and then contrasted with the edited versions of RAs. For space considerations, and to have easier comparisons, we will be presenting the first two sections, Introduction and Method, and then the sections Results and Discussion side by side for a brief review of the MD items in these sections and possible points of contrast. Having done so, however, we will be reviewing the use of subcategories of Interactional/ and Interactive MD in isolation.

\subsection{MD elements in four sections of RAs}

As seen in Table 2, there is a huge gap between the instances of Interactive and Interactional MD elements used in the Introduction section, with the Interactive items far outnumbering the Interactional ones (152 vs. 55). However, this huge 
gap changes to a veritable chasm in the Method section where there are only 7 Interactional MD markers against 104 Interactive ones. The reason might be attributed to the fact that more textual devices are required in the Method section to convey propositional meanings in a cohesive and coherent text rather than to express an author's personal and evaluative comments through the use of Interactional devices (Vande Kopple, 2002).

\begin{tabular}{|c|c|c|c|c|c|c|c|c|c|c|c|}
\hline & \multirow[t]{2}{*}{ MD Elements } & \multicolumn{2}{|c|}{ Unedited } & \multicolumn{2}{|c|}{$\begin{array}{l}\text { Added in } \\
\text { editing }\end{array}$} & \multicolumn{2}{|c|}{ Total No. } & \multicolumn{2}{|c|}{$\%$ Edit } & \multicolumn{2}{|c|}{$\%$ Total } \\
\hline & & Int* & $\mathrm{Me}^{* *}$ & Int & $\mathrm{Me}$ & Int & $\mathrm{Me}$ & Int & $\mathrm{Me}$ & Int & $\overline{\mathrm{Me}}$ \\
\hline \multirow{5}{*}{ 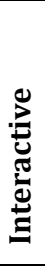 } & Transitions & 57 & 26 & 13 & 8 & 70 & 34 & 18.6 & 23.5 & 27.9 & 21.9 \\
\hline & Frame Markers & 19 & 27 & 9 & 7 & 28 & 34 & 32.1 & 20.6 & 11.2 & 21.9 \\
\hline & Evidentials & 6 & 6 & 3 & 0 & 9 & 6 & 33.3 & 0.0 & 3.6 & 3.9 \\
\hline & Code Glosses & 29 & 6 & 1 & 0 & 30 & 6 & 3.3 & 0.0 & 12.0 & 3.9 \\
\hline & $\begin{array}{l}\text { Endophoric } \\
\text { Markers }\end{array}$ & 15 & 24 & 0 & 0 & 15 & 24 & 0.0 & 0.0 & 6.0 & 15.5 \\
\hline \multirow{5}{*}{ 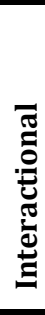 } & Hedges & 16 & 1 & 4 & 0 & 20 & 1 & 20.0 & 0.0 & 8.0 & 0.6 \\
\hline & Boosters & 2 & 2 & 4 & 1 & 6 & 3 & 66.7 & 33.3 & 2.4 & 1.9 \\
\hline & $\begin{array}{l}\text { Attitude } \\
\text { Markers }\end{array}$ & 18 & 2 & 10 & 1 & 28 & 3 & 35.7 & 33.3 & 11.2 & 1.9 \\
\hline & Self-mentions & 1 & 0 & -10 & 0 & -9 & 0 & 0.0 & 0.0 & 0.4 & 0.0 \\
\hline & $\begin{array}{l}\text { Engagement } \\
\text { Markers }\end{array}$ & 0 & 0 & 0 & 0 & 0 & 0 & 0.0 & 0.0 & 0.0 & 0.0 \\
\hline \multirow{5}{*}{ 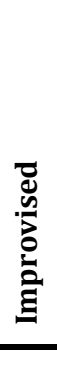 } & $\begin{array}{l}\text { Code Glosses } \\
\text { Parentheses }\end{array}$ & 3 & 37 & 0 & 0 & 3 & 37 & 0.0 & 0.0 & 1.2 & 23.9 \\
\hline & $\begin{array}{l}\text { Frame Marker } \\
\text { Phrases }\end{array}$ & 8 & 5 & 4 & 0 & 12 & 5 & 33.3 & 0.0 & 4.8 & 3.2 \\
\hline & $\begin{array}{l}\text { Frame Marker } \\
\text { Clauses }\end{array}$ & 5 & 1 & 6 & 1 & 11 & 2 & 54.5 & 50.0 & 4.4 & 1.3 \\
\hline & $\begin{array}{l}\text { Secondary Self- } \\
\text { mentions }\end{array}$ & 18 & 0 & 0 & 0 & 18 & 0 & 0.0 & 0.0 & 7.2 & 0.0 \\
\hline & Total & 197 & 137 & 44 & 18 & 241 & 155 & 21.5 & 11.6 & 100.3 & 99.9 \\
\hline
\end{tabular}

Table 2. MD devices observed in the Introduction and Method sections

Furthermore, the editing process seems to have done little in this regard. If anything, it widened the gap rather than bridging it. For instance, in the Method section, compare the addition of 15 Interactive devices against only 2 Interactional ones which are essentially supposed to establish author-reader relationship. After all, editing, by definition, is supposed to iron out problem areas, providing for effective communication between the original author and the prospective reader (Beuhler, 2003). As such, one would expect to encounter some evidence of the editors' awareness of this discrepancy, and their attempts to make amends for the author's possible oversights. In other words, if the authors are to blame for inappropriate use of MD devices in this section, the editor can hardly be spared 
and one may not be able to credit the editors with serious attempts to alter the scene, either.

\begin{tabular}{|c|c|c|c|c|c|c|c|c|c|c|c|}
\hline & \multirow{2}{*}{ MD Elements } & \multicolumn{2}{|c|}{ Unedited } & \multicolumn{2}{|r|}{$\begin{array}{r}\text { Added in } \\
\text { editing }\end{array}$} & \multicolumn{2}{|r|}{ Total No. } & \multicolumn{2}{|c|}{$\%$ Edit } & \multicolumn{2}{|c|}{$\%$ Total } \\
\hline & & $\mathrm{Re}^{*}$ & Dis** & $\mathrm{Re}$ & Dis & $\mathrm{Re}$ & Dis & $\operatorname{Re}$ & Dis & $\mathrm{Re}$ & Dis \\
\hline \multirow{5}{*}{ 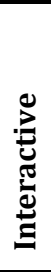 } & Transitions & 20 & 87 & 15 & 24 & 35 & 111 & 42.9 & 21.6 & 23.0 & 31.5 \\
\hline & Frame Markers & 19 & 19 & 7 & 3 & 26 & 22 & 26.9 & 13.6 & 17.1 & 6.3 \\
\hline & Evidentials & 4 & 30 & 3 & 1 & 7 & 31 & 42.9 & 3.2 & 4.6 & 8.8 \\
\hline & Code Glosses & 2 & 9 & 1 & 1 & 3 & 10 & 33.3 & 10.0 & 2.0 & 2.8 \\
\hline & $\begin{array}{l}\text { Endophoric } \\
\text { Markers }\end{array}$ & 45 & 32 & 3 & 8 & 48 & 40 & 6.3 & 20.0 & 31.6 & 11.4 \\
\hline \multirow{5}{*}{ 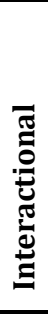 } & Hedges & 1 & 43 & 0 & 4 & 1 & 47 & 0.0 & 8.5 & 0.7 & 13.4 \\
\hline & Boosters & 1 & 2 & 0 & 0 & 1 & 2 & 0.0 & 0.0 & 0.7 & 0.6 \\
\hline & $\begin{array}{l}\text { Attitude } \\
\text { Markers }\end{array}$ & 2 & 12 & 3 & 1 & 5 & 13 & 60.0 & 7.7 & 3.3 & 3.7 \\
\hline & Self-mentions & 0 & 5 & 0 & 1 & 0 & 6 & 0.0 & 16.7 & 0.0 & 1.7 \\
\hline & $\begin{array}{l}\text { Engagement } \\
\text { Markers }\end{array}$ & 0 & 0 & 0 & 0 & 0 & 0 & 0.0 & 0.0 & 0.0 & 0.0 \\
\hline \multirow{5}{*}{ 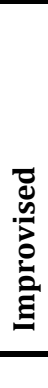 } & $\begin{array}{l}\text { Code Glosses } \\
\text { Parentheses }\end{array}$ & 21 & 12 & 0 & 0 & 21 & 12 & 0.0 & 0.0 & 13.8 & 3.4 \\
\hline & $\begin{array}{l}\text { Frame Marker } \\
\text { Phrases }\end{array}$ & 2 & 15 & 0 & 0 & 2 & 15 & 0.0 & 0.0 & 1.3 & 4.3 \\
\hline & $\begin{array}{l}\text { Frame Marker } \\
\text { Clauses }\end{array}$ & 3 & 11 & 0 & 0 & 3 & 11 & 0.0 & 0.0 & 2.0 & 3.1 \\
\hline & $\begin{array}{l}\text { Secondary Self- } \\
\text { mentions }\end{array}$ & 0 & 32 & 0 & 0 & 0 & 32 & 0.0 & 0.0 & 0.0 & 9.1 \\
\hline & Total & 120 & 309 & 32 & 43 & 152 & 352 & 211 & 12.2 & 100.1 & 100.1 \\
\hline
\end{tabular}

Table 3. MD devices observed in the Results and Discussion sections

As Table 3 illustrates, the Interactive resources were still dominating Results and Discussion sections compared to their Interactional counterparts, and the editing process seems to have seen to it that the discrepancy stays on or gets even more noticeable. If the communicative purpose of the Method section and its requirements could serve as a ground to justify a relatively low use of Interactional devices in that section - though nowhere near what was observed in our data - the same can surely not be said about the Results section. This is where one expects the author to make their presence felt through alerting "readers to the author's perspective towards both the propositional information and the readers themselves, thus contributing to a writer-reader relationship and anticipating the subjective negotiability of statements" (Hyland, 1998: 443).

The finding that Interactive MD markers outnumbered Interactional ones in our data does not seem to constitute a deviation from the NES authors' norms as reported by several other researchers working on RAs produced by primarily NES 
authors (Hyland, 1998; Mu, Zhang, Ehrich, \& Hong, 2015; Zarei \& Mansoori, 2007). However, while the Interactive MD is used roughly $20 \%$ more frequently than Interactional MD in NES data in Hyland (1998), the only author to have provided a detailed account of MD counts, this discrepancy was observed at an outlandish proportion of $400 \%$ in our data. When this is coupled with the observation that NNES authors have used MD devices almost half as frequently as the NES authors (Table 4), the obvious conclusion is NNES authors in our dataset have seriously underused Interactional elements, perhaps less than $15 \%$ of what one would expect to encounter in NES author's papers.

\begin{tabular}{|c|c|c|c|c|c|c|c|}
\hline & $\begin{array}{c}\text { MD } \\
\text { Elements }\end{array}$ & Unedited & $\begin{array}{r}\text { Added in } \\
\text { editing }\end{array}$ & $\begin{array}{c}\text { Total } \\
\text { No. }\end{array}$ & $\%$ Edit & $\%$ Section & \% Total \\
\hline \multirow{5}{*}{ 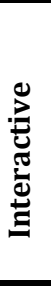 } & Transitions & 190 & 60 & 250 & 24.0 & 42.4 & 27.5 \\
\hline & Frame Markers & 84 & 26 & 110 & 23.6 & 18.7 & 12.1 \\
\hline & Evidentials & 46 & 7 & 53 & 13.2 & 9.0 & 5.8 \\
\hline & Code Glosses & 46 & 3 & 49 & 6.1 & 8.3 & 5.4 \\
\hline & $\begin{array}{l}\text { Endophoric } \\
\text { Markers }\end{array}$ & 116 & 11 & 127 & 8.7 & 21.6 & 14.0 \\
\hline \multirow{5}{*}{ 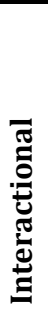 } & Hedges & 61 & 8 & 69 & 11.6 & 50.4 & 7.6 \\
\hline & Boosters & 7 & 5 & 12 & 41.7 & 8.8 & 1.3 \\
\hline & $\begin{array}{l}\text { Attitude } \\
\text { Markers } \\
\end{array}$ & 34 & 15 & 49 & 30.6 & 35.8 & 5.4 \\
\hline & Self-mentions & 16 & -9 & 7 & 14.3 & 5.1 & 0.8 \\
\hline & $\begin{array}{l}\text { Engagement } \\
\text { Markers } \\
\end{array}$ & 0 & 0 & 0 & 0.0 & 0.0 & 0.0 \\
\hline \multirow{5}{*}{ 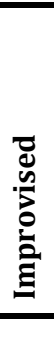 } & $\begin{array}{l}\text { Code Glosses } \\
\text { Parentheses }\end{array}$ & 73 & 0 & 73 & 0.0 & 39.7 & 8.0 \\
\hline & $\begin{array}{l}\text { Frame Marker } \\
\text { Phrases }\end{array}$ & 30 & 4 & 34 & 11.8 & 18.5 & 3.7 \\
\hline & $\begin{array}{l}\text { Frame Marker } \\
\text { Clauses }\end{array}$ & 20 & 7 & 27 & 25.9 & 14.7 & 3.0 \\
\hline & $\begin{array}{l}\text { Secondary Self- } \\
\text { mentions }\end{array}$ & 50 & 0 & 50 & 0.0 & 27.2 & 5.5 \\
\hline & Total & 773 & 137 & 910 & 16.2 & 300.2 & 100.1 \\
\hline
\end{tabular}

Table 4. Total MD devices observed in the data

\subsection{Individual MD Elements}

Overall, a total of $910 \mathrm{MD}$ elements were recorded in our data which consisted of 31,068 words; on average $1 \mathrm{MD}$ device per roughly every 34 words. This figure in Hyland (1998) was about 1 MD element per every 15 words. That is, NES manuscripts, on average, contain twice as many MD markers as the NNES productions in our data. To get a more intimate understanding of the situation, the 
occurences of individual MD elements in the two categories are illustrated in Figure 1 and also discussed below one by one. It must be added that the four MD elements added under the improvised category are for the purpose of enhancing the comprehensiveness of our dataset and will not be considered in our main discussion so as to retain the comparability of our research with other works.

\subsubsection{Interactive MD Elements}

Transitions. The Transition category was by far the most frequently employed of MD categories in the unedited manuscripts in our data, comprising $27.5 \%$ of all MD elements observed, and as such it was also the category which had the highest instances of the markers added or modified in the editing process. However, compared with the total number of MD markers added in the editing process, the number of Transition signals was proportionally not too much higher than the average, i.e. $24 \%$. An important point to be mentioned is the fact that the editing in this category was not all about adding up Transition elements to create semantic relations overlooked by the author. Rather, it was more about replacing a Transition marker with a more appropriate one (e.g. replacing also with furthermore). The reason for this observation might lie in the fact that the authors in our study were all academic staff members, fluent and experienced authors in their own language, and thus most of them were attentive to the use of Transition markers, being aware of the significant role that they can play in enhancing the cohesion and coherence of their texts. Of course, the downside of transferring L1 skills to writing in L2 might be, as it were, the use of Transition signals which are grammatically, and semantically correct, but contextually inappropriate.

Moreover, Transitions were the most evenly distributed of all other categories in the four sections of the RAs. While the number increased in the Discussion section, and slightly fell in the Method section, all four sections got their fair share of Transition signals overall. This might have resulted from both the nature of the functions that Transition signals fulfill and the skill of the authors in employing these elements. Perhaps that is why the frequency of Transitions, proportionately at least, resembles that reported for NES products, as for instance Liu and Buckingham (2018) also reported this category as the most frequently employed of textual markers, especially in the Discussion section, in their dataset.

Endophoric Markers. They were the second most frequently used MD elements (about 14\%), and had evoked proportionally the least editing, i.e. less than 10\%. At first glance, one is tempted to assume that the authors have somehow done well in this particular category of MD - judging from the frequency of this element in comparison with others; however, the authors' apparently good performance in this category should not signify their boosted proficiency level in this area. Upon closer examination, it is not difficult to see how the authors managed to easily make reference to other parts of their manuscripts - the function of Endophoric 
Markers - without having a matching proficiency level in other categories. The primary reason, we assume, is the fact that Endophoric Markers actually consist of rather formulaic chunks, which are not too demanding to acquire after all, especially when one does not feel too obliged to add some variety to the use of such phrases. This might also serve as the reason why the editors did not seem to have shown much interest in this category.

Frame Markers. Frame markers were the third most commonly used of the MD elements observed in the RAs in our study (12.1\%). Moreover, regarding editing, Frame Markers were the second most frequently added elements (23.6\%). Part of the reason for the frequent use of this category might well have to do with the tendency of Iranian authors to use contextualizing elements (e.g. prior to the presentation of..., after it was completed) at the beginning of their sentences, which is probably the result of transferring the norms of using contextualizing elements in their mother tongue (Zarei \& Mansoori, 2007). Burgess, Fumero Pérez, and Díaz Galán (2005), contrasting the edited and original versions of RAs in Spanish, also pointed out that the mismatch between NNES authors and the expectations of international discourse community often occurs at rhetorical and structural level. Such contextualizing elements in English are known to occur in virtually all positions in the sentence, i.e. initial, final or even the middle of sentences with commas used to separate them, and if the contextualizing element happens to be a clause the norm is for the dependent clause to follow the main clause in English (Halliday, 1985).

As was mentioned above, we counted such elements separately as MD devices after we got Hyland's approval on our modification through personal Email, but did not involve them in the category of Frame Markers. The number of Frame Marker devices would be considerably higher if they had been identified in accordance with our broader definition, which is if we had added the Frame Markers elements in the 'Improvised' category, namely, projecting clauses, and contextualizing phrases which are not included in Hyland's model despite their meta-discoursal function. Of course, projecting clauses were found to be more frequently used by Iranian authors than NES authors since it is the norm in their first language (Farsi).

Frame markers refer to discourse acts (e.g. to conclude) or sequences or stages in the text (e.g. finally, after that), which are important resources aiding the author in effective text management (Hyland, 2005). What was conspicuously unnatural about the instances of the use of Frame Markers in our data was the fact that Frame Markers used in our data were predominantly of the latter type, referring to stages and sequences - hence the highest frequency in the Method section. Their use in the Discussion section is, by contrast, the lowest of all other sections. We call this unnatural because Frame Markers are an important source of text management to announce discourse goals, topic shifts, etc. which can be done best in the Discussion where the author's own voice is supposed to be echoed. 
Thus, a relatively high number indicating high instance of the use of a particular category should not give the impression that the category in question is better learned than others by NNES. We should probe deeper into the source of the numbers to access the facts behind the figures, and then make the right decisions regarding how to deal with the problems surfacing afterwards. The authors' inability to express the discourse goal, refer to discourse acts, etc. is among the instances of their failure to make their presence felt to the reader, a problem that can seriously compromise the perceived quality of a manuscript.

Evidentials and Code Glosses. These are the most sparsely used of the Interactive MD elements. Part of the reason for infrequent use of Evidentials might have had to do with the fact that the journal was a number referenced one, in which particular authors are not frequently referred to by name to specify the source, and we did not include the numbers as instances of MD. The Code Glosses being underused, however, could have resulted from the fact that the MD elements in this category are usually those calling on the author to provide further elaboration or clarifications regarding a particular item or part of a text. The NNES authors might have deliberately avoided Code Glosses elements due to the lack of sufficient linguistic proficiency required for more elaboration and exemplifications.

When such elaborations were deemed necessary, the authors seemed to resort to the use of parentheses, which would not have required them to announce their presence linguistically - hence the rather high frequency of Code Glosses Phrases (a total of 73 instances, with 37 in the Method section).The editing of these categories was done quite infrequently and below the average $113 \%$ and $6 \%$ for Evidentials and Code Glosses, respectively). It is clear that these two categories are different from the other categories of Interactive MD in Hyland's model in terms of the frequency of their occurrence and their editing.

\subsubsection{Interactional MD elements}

Hedges. Hedges, with a total of 66 instances of use were the most frequently used of all Interactional categories, with roughly $12 \%$ of hedging elements added in the editing process compared with 223 instances of Transition in the Interactive MD. The fact that $12 \%$ of Hedges elements have been added in the editing process was rather below the expected rate, and it would have come as little surprise if we had found a lot more instances of hedging added in the editing process for the simple reason that Iranians use hedging sparsely in their communication, and are prone to do likewise when they communicate in English (Tahririan \& Shahzamani, 2009). Thus, as with the other devices investigated so far, the editing process seems to have brought about few significant changes in this regard. In other words, if the authors can be blamed for underusing Hedges in their writing, almost the same can be said about the editors. 
Attitude Markers and Boosters. Attitude markers were the second most frequently used of Interactional categories (49 instances), with 15 added in the editing process, a little more than 30\%. Originally a total of 7 Boosters had been used in our data, 5 of them were added in the editing process, which is about $41 \%$. However, the NNES authors have long way to go to come anywhere close to the NES standards in terms of MD use in general and Interactional MD in particular. Note that there were only 7 instances of Boosters used in 20 RAs (almost 1 per every 3 RAs), and the editing has added 5 in total (making it roughly 1 per every 2 RAs). Admittedly, the Interactional devices, by nature, mostly serve argumentative and explanatory purposes (Liu \& Buckingham, 2018), echoing the authors' own attitudes to their material and readers (Hyland \& Jiang, 2017), and these might not be the most appropriate areas where editors could rightfully be expected to make extensive modifications. This is probably strong enough evidence to suggest that the original authors should cooperate with editors, availing themselves of their linguistic resources to establish the necessary connection with their texts and readers. The interaction between authors and 'text mediators' have been highlighted as possessing a rich potential to inform both text mediation practices and revision research (Luo \& Hyland, 2017), as well as a major resource to enhance the quality of the manuscript.

Engagement Markers. Interestingly enough, there was not even a single instance of Engagement Markers used in any of the 20 RAs in our data, which further highlights how poor NNES authors could be in establishing a relationship with their prospective readers. Hyland and Jiang (2016: 10) defined Engagement Markers as "the ways authors rhetorically acknowledge the presence of their readers in a text [...] It therefore turns on the degree to which authors present themselves as sharing, or perhaps failing to share, attitudes and how they manage solidarity and affiliation". What is certain is that Engagement Markers cannot be structurally so complex as to be elusive to all authors in our data. Thus, one possible reason might be that NNES authors are simply too preoccupied with the propositional aspect of their product that they become oblivious of accommodating the prospective readers, drawing on MD resources like Engagement Markers or Code Glosses. Nor do the editors seem to acknowledge the significance of Engagement Markers so as to make modifications in this regard, probably setting lexico-grammatical correctness as their first priority.

Self-Mentions. It was the only device of all MD markers, whether Interactive or Interactional, which was found to have been reduced in the editing process. There were 16 instances of Self-mentions in the original RAs - one was added in the editing process whereas 10 instances were deleted in the editing process, with as few as 7 instances of Self-mentions remaining in the whole data set. It has frequently been emphasized that an impersonal tone must be maintained in academic writing, and it would seem that the editing has been an attempt to lower 
human-face discourse, maintaining an impersonal voice. Yet, a successful piece of writing would hinge on establishing the right balance between personal and impersonal tone, surely not by deleting one altogether (Gosden, 1993). As for the Secondary Self-mentions category, with a comparatively significant instance of use (50 in total), we only decided that in a number referenced journal, when an author is referred to by name, special significance must be attached to it, and thus all instances of Secondary Self-mentions were counted in our data.

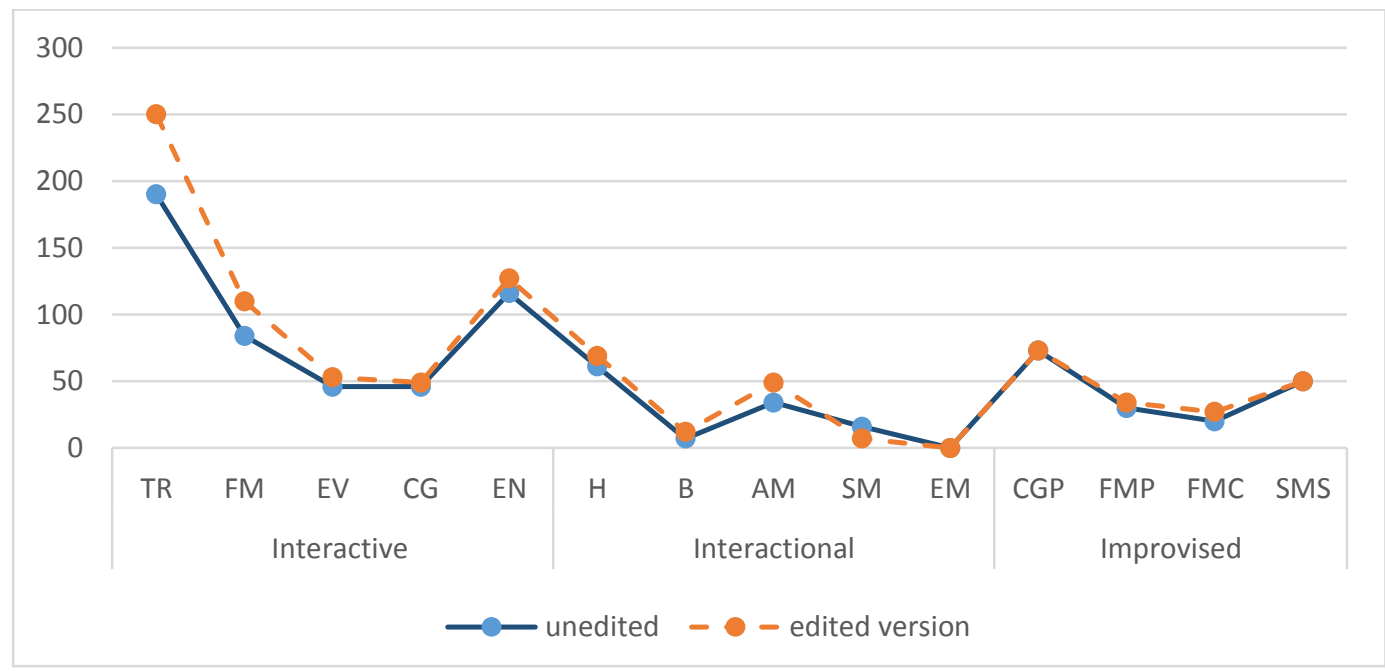

Figure 1. The effect of editing on the frequency of MD markers

\section{CONCLUSION}

MD is almost unanimously agreed to involve "material which helps readers to organize, interpret and evaluate what is being said" (Hyland, 2017: 17), and its functions include "making authorial presence felt in the text, expressing the author's direction for how readers should read [and] react to [...] what they have written about the subject matter" (Ädel, 2006: 170). Thus, given the central role accorded to MD, and the fact that the NNES authors are found to have severely underused MD elements in comparison to the NES authors, it might be safe to conclude that the NNES authors, in practice, are failing to provide the required commentary which could serve as authorial interventions to ease negotiation of meaning and as authorial guide which could facilitate the reading process and readers' interpretation of the text.

Another point worthy of note is the fact that the NES writers seem to make full use of communicative potentials of MD categories, drawing on all MD categories in their productions. However, the MD subcategories in our data, especially the Interactional ones, have been used in a fundamentally different manner, most being significantly underused and one utterly neglected. On the 
other hand, the Interactive elements were found to be consistently outnumbering Interactional elements in each and every section of the RAs, sometimes in bizarre proportions, being used $400 \%$ more than their Interactional counterparts on average, while this figure is only about $20 \%$ more in NES manuscripts.

The Iranian students at ESP classes, especially at the post graduate level, are excessively concerned with lexico-grammar and cohesive devices, which might explain the high frequency of Transitions in the manuscripts of Iranian authors, most of whom are graduates from Iranian universities. However, such preoccupation with lexio-grammar happens at the expense of elements promoting reader-friendliness of the text (e.g. Evidentials and Code Glosses are the least frequently used of Interactive MD) or providing for interpersonal considerations of writing (e.g. the low frequency of almost all Interactional elements). In other words, the NNES authors in our study utterly lack the capability to interact with their readers or to provide adequate guidance through Evidentials and Code Glosses, to express their evaluative comments through Attitude Markers and Boosters in order to establish and maintain a successful relationship between themselves and the readers - hence the conspicuous absence of Engagement Markers from the whole data set. As it was pointed out by Khalili, Farrokhi, and Aslanabadi (2016), the Iranian authors' lack of proficiency to give voice to their own thinking and expressing their views is a major problem that is manifest in their research article move structure as well. These obvious shortcomings in NNES manuscripts seem to have escaped the editors' attention as their interventions seldom make tangible changes in the existing proportions among MD items, with the high-frequency items in the manuscripts often added most frequently in the editing process.

Of course, there were a few confounding factors which may have contributed to the marked divergence of our data from the NES data as reported by Hyland (1998). His corpus included both hard and soft sciences, and the paper length in his data was 5,500 words on average while our corpus comprised only dentistry RAs mostly containing less than 2,000 words. However, even after one corrected the findings for such factors which are known to influence the density and frequency of MD elements e.g. disciplinary variation (Hyland, 2004; Kawase, 2015) and genre or paper length (Khedri et al., 2013), one would still be left with too big a gap unaccounted for.

The need for further research has to be emphasized here, with extraneous factors like paper length and disciplinary variation provided for, so that we could be in a better position to generalize our findings with a decent degree of certainty. However, even at this stage, it is believed, our findings might provide important implications for the ESP program designers and teachers alike, as well as the editors who edit academic manuscripts written by NNES authors. The RA writing classes frequently held for academic staff members have traditionally been excessively concerned with the generic conventions of the RA, combined with some formulaic expressions specific to particular parts of a RA. Nevertheless, little is said about how the authors could accommodate suasion in the propositional content of 
their paper so that their product is effectively organized, conveys their convictions, takes account of the readers' knowledge and reactions, etc. However strange this may sound, it might be a good idea to accommodate the most productive authoreditor relationships in such classes in an attempt to overcome practical difficulties. If the instrumental role that skilled editors could play in the publishing success is acknowledged in such classes, the authors could be encouraged to give more credit to the editors, specially English experts because, as Shashok (2001) noted, the editors often go beyond mere linguistic corrections, effectively acting as writing advisors who edit texts, educate authors and defend their rights.

The implications for the editors seem obvious because the editing, which is expected to push the NNES manuscripts toward NES norms in every possible way, does not seem to have been quite efficient with regard to the use of MD elements. It would not be illogical to expect the edited draft to contain tangible improvement tendencies which would be a measure of the editor's familiarity with the norms of academic writing in English, as well as their awareness of the paper's shortcomings. We suggest that editing in the present situation should be a collaborative process, in which the editor should embolden the author/scholar, by helping them overcome their linguistic difficulties, to make authorial interventions, provide reader guidance and accommodate the readers' reactions. However, practical considerations arising from the nature of scientific writing might complicate the feasibility of such cooperation. Shaw and Voss (2017) provided possible reasons which might hinder fruitful author-editor interactions. For instance, authors might be unwilling to cooperate with 'correctors', because they may not share the same attitude regarding the correctors' role, believing that the 'correctors' should only focus on the spelling and grammar and never approach the content, or authors might be so pressed for time that they might expect the work to be finished by the editors alone. As it is also remarked by Burgess and Lillis (2013: 13), "professional isolation, however, makes it difficult to share learning, and even more so when we consider the full range of writing support rather than taking a restricted view limited to activities such as translation or copy-editing". Therefore, the best possible result, which is the publication of the RAs in highly credited journals, can be gained if editors, either language professionals or subject specialists, share their observations of the text with the authors throughout the editing process.

[Paper submitted 30 Aug 2019]

[Revised version received 10 Dec 2019]

[Revised version accepted for publication 22 Dec 2019]

\section{References}

Ädel, A. (2006). Metadiscourse in L1 and L2 English. Amsterdam, Netherlands: John Benjamins. https://doi.org/10.1075/scl.24

Beuhler, M. F. (2003). Situational editing: A rhetorical approach for the technical editor. Technical Communication, 50(4), 458-464. 
Bisaillon, J. (2007). Professional editing strategies used by six editors. Written Communication, 24(4), 295-322. https://doi.org/10.1177/0741088307305977

Blagojević, S. (2004). Metadiscourse in academic prose: A contrastive study of academic articles written in English by English and Norwegian speakers. Studies about Linguistics, 5, 1-7.

Burgess, S., \& Lillis, T. (2013). The contribution of language professionals to academic publication: Multiple roles to achieve common goals. In V. Matarese (Ed.), Supporting research writing: Roles and challenges in multilingual settings (pp. 1-15). Oxford, UK: Chandos. https://doi.org/10.1016/b978-1-84334-666-1.50001-1

Burgess, S., Fumero Pérez, M. C., \& Díaz Galán, A. (2005). Mismatches and missed opportunities? A case study of a non-English speaking background research writer. In M. L. Carretero, L. Hidalgo Downing, J. Lavid, E. Martínez Caro, J. Neff, S. Pérez de Ayala, \& E. Sánchez-Pardo (Eds.), A pleasure of life in words: A festschrift for Angela downing (pp. 283-304). Madrid: Universidad Complutense de Madrid.

Burrough-Boenish, J. (2003). Shapers of published NNS research articles. Journal of Second Language Writing, 12(3), 223-243. https://doi.org/10.1016/s1060-3743(03)00037-7

Coates, R. B., Sturgeon, B., Bohannan, J., \& Pasini, E. (2002). Language and publication in cardiovascular research articles. Cardiovascular Research, 53(2), 279-285. https://doi.org/10.1016/s0008-6363(01)00530-2

Crismore, A., Markkanen, R., \& Steffensen, M. (1993). Metadiscourse in persuasive writing: A study of texts written by American and Finnish university students. Written Communication, 10, 39-71. https://doi.org/10.1177/0741088393010001002

Dahl, T. (2004). Textual metadiscourse in research articles: A marker of national culture or of academic discipline? Journal of Pragmatics, 36(10), 1807-1825. https://doi.org/10.1016/j.pragma.2004.05.004

Ehara, S., \& Takahashi, K. (2007). Reason for rejection of manuscripts submission to AJR by international authors. American Journal of Roentgenology, 188, 113-116. https://doi.org/10.2214/ajr.06.0448

Ferguson, G. (2007). The global spread of English, scientific communication and ESP: Questions of equity, access and domain loss. Ibérica, 13, 7-38.

Flowerdew, J., \& Wang, S. H. (2016). Author's editor revisions to manuscripts published in international journals. Journal of Second Language Writing, 32, 39-52. https://doi.org/10.1016/j.jslw.2016.03.004

Gosden, H. (1993). Discourse functions of subject in scientific research articles. Applied Linguistics, 14(1), 56-75. https://doi.org/10.1093/applin/14.1.56

Halliday, M. A. (1985). An introduction to functional linguistics. London: Edward Arnold.

Huang, J. C. (2010). Publishing and learning writing for publication in English: Perspectives of NNES PhD students in science. Journal of English for Academic Purposes, 9(1), 33-44. https://doi.org/10.1016/j.jeap.2009.10.001

Hultgren, A. K. (2019). English as the language for academic publication: On equity, disadvantage and 'non-nativeness' as a red herring. Publications, 7(2), 31-43.

Hyland, K. (1998). Hedging in scientific research articles. Amsterdam, Netherlands: John Benjamins.

Hyland, K. (2004). Disciplinary discourses: Social interactions in academic writing. Ann Arbor, MI: University of Michigan Press.

Hyland, K. (2005). Stance and engagement: A model of interaction in academic discourse. Discourse Studies, 7(2), 173-191. https://doi.org/10.1177/1461445605050365 
Hyland, K. (2016). Academic publishing and the myth of linguistic injustice. Journal of Second Language Writing, 31, 58-69. https://doi.org/10.1016/j.jslw.2016.01.005

Hyland, K. (2017). Metadiscourse: What is it and where is it going? Journal of Pragmatics, 113, 16-29. https://doi.org/10.1016/j.pragma.2017.03.007

Hyland, K., \& Jiang, F. (2016). Change of attitude? A diachronic study of stance. Written Communication, 33(3), 1-24. https://doi.org/10.1177/0741088316650399

Hyland, K., \& Jiang, F. (2017). Is academic writing becoming more informal? English for Specific Purposes, 45, 40-51. https://doi.org/10.1016/j.esp.2016.09.001

Hyland, K., \& Tse, P. (2004). Metadiscourse in scholastic writing: A reappraisal. Applied Linguistics, 25(2), 156-177. https://doi.org/10.1093/applin/25.2.156

Kawase, T. (2015). Metadiscourse in the introductions of $\mathrm{PhD}$ theses and research articles. Journal of English for Academic Purposes, 20, 114-124. https://doi.org/10.1016/j.jeap.2015.08.006

Khalili, A., \& Aslanabadi, M. (2014). The use of metadiscourse devices by non-native speakers in research articles. The Journal of Applied Linguistics and Discourse Analysis, 2(2), 21-34.

Khalili, A., Farrokhi, F., \& Aslanabadi, M. (2016). Application of native speaker models for identifying deviations in rhetorical moves in non-native speaker manuscripts. Research and Development in Medical Education, 5(1), 18-26. https://doi.org/10.15171/rdme.2016.005

Khedri, M., Heng, C. S., \& Ebrahimi, S. F. (2013). An exploration of interactive metadiscourse markers in academic research article abstracts in two disciplines. Discourse Studies, 15(3), 319-331. https://doi.org/10.1177/1461445613480588

Koyalan, A., \& Mumford, S. (2011). Changes to English as an additional language writers' research articles: From spoken to written register. English for Specific Purposes, 30(2), 113-123. https://doi.org/10.1016/j.esp.2010.10.001

Li, Y., \& Flowerdew, J. (2007). Shaping Chinese novice scientists' manuscripts for publication. Journal of Second Language Writing, 16(2), 100-117. https://doi.org/10.1016/j.jslw.2007.05.001

Lillis, T., \& Curry, M. J. (2006). Professional academic writing by multilingual scholars: Interactions with literacy brokers in the production of English medium texts. Written Communication, 23(1), 3-35. https://doi.org/10.1177/0741088305283754

Lillis, T., \& Curry, M. J. (2010). Academic writing in a global context: The politics and practices of publishing in English. London: Routledge.

Liu, Y., \& Buckingham, L. (2018). The schematic structure of discussion sections in applied linguistics and the distribution of metadiscourse markers. Journal of English for Academic Purposes, 34, 97-109. https://doi.org/10.1016/j.jeap.2018.04.002

Luo, N., \& Hyland, K. (2016). Chinese academics writing for publication: English teachers as text mediators. Journal of Second Language Writing, 33, 43-55. https://doi.org/10.1016/j.jslw.2016.06.005

Luo, N., \& Hyland, K. (2017). Intervention and revision: Expertise and interaction in text mediation. Written Communication, 34, 414-440. https://doi.org/10.1177/0741088317722944

Marandi, S. (2003). Metadiscourse in Persian/English master's theses: A contrastive study. Iranian Journal of Applied Linguistics, 6(2), 23-42.

Mauranen, A. (1993). Cultural differences in academic writing. Berlin: Peter Lang.

$\mathrm{Mu}, \mathrm{C} .$, Zhang, L. J., Ehrich, J., \& Hong, H. (2015). The use of metadiscourse for knowledge construction in Chinese and English research articles. Journal of English for Academic Purposes, 20, 135-148. https://doi.org/10.1016/j.jeap.2015.09.003 
Pérez-Llantada, C. (2010). The discourse functions of metadiscourse in published academic writing: Issues of culture and language. Nordic Journal of English Studies, 9(2), 41-68. https://doi.org/10.35360/njes.217

Salas, M. D. (2015). Reflexive metadiscourse in research articles in Spanish: Variation across three disciplines (linguistics, economics and medicine). Journal of Pragmatics, 77, 20-40. https://doi.org/10.1016/j.pragma.2014.12.006

Salager-Meyer, F. (2008). Scientific publishing in developing countries: Challenges for the future. Journal of English for Academic Purposes, 7(2), 121-132. https://doi.org/10.1016/j.jeap.2008.03.009

Shashok, K. (2001). Author's editors: Facilitators of science information transfer. Learned Publishing, 14, 113-121. https://doi.org/10.1087/095315101300059495

Shaw, 0., \& Voss, S. (2017). The delicate art of commenting: Exploring different approaches to editing and their implications for the author-editor relationship. In M. Cargill, \& S. Burgess (Eds.), Publishing research in English as an additional language: Practice, pathways and potentials (pp. 71-86). Adelaide, Australia: University of Adelaide Press. https://doi.org/10.20851/english-pathways-04

Tahririan, M. H., \& Shahzamani, M. (2009). Hedging in English and Persian editorials: A contrastive study. Iranian Journal of Applied Linguistics, 12(1), 199-221.

Vande Kopple, W. J. (1985). Some explanatory discourse on metadiscourse. College Composition and Communication, 36(1), 82-93. https://doi.org/10.2307/357609

Vande Kopple, W. J. (2002). Metadiscourse, discourse, and issues in composition and rhetoric. In F. Barton, \& C. Stygall (Eds.), Discourse studies in composition (pp. 91113). Cresskill, NJ: Hampton Press.

Willey, I., \& Tanimoto, K. (2012). 'Convenience editing' in action: Comparing English teachers' and medical professionals' revisions of a medical abstract. English for Specific Purposes, 31(4), 249-260. https://doi.org/10.1016/j.esp.2012.04.001

Willey, I., \& Tanimoto, K. (2013). 'Convenience editors' as legitimate participants in the practice of scientific editing: An interview study. Journal of English for Academic Purposes, 12, 23-32. https://doi.org/10.1016/j.jeap.2012.10.007

Willey, I., \& Tanimoto, K. (2015). 'We're drifting into strange territory here': What thinkaloud protocols reveal about convenience editing. Journal of Second Language Writing, 27, 63-83. https://doi.org/10.1016/j.jslw.2014.09.010

Zarei, G. R., \& Mansoori, S. (2007). Metadiscourse in academic prose: A contrastive analysis of English and Persian research articles. The Asian ESP Journal, 3(2), 24-40.

ASSEF KHALILI received his Ph.D. degree in English language teaching from Tabriz University, Iran. He has been teaching EGP and EAP courses since 2004. His research interests include discourse analysis, genre analysis, teaching and learning ESP and EAP, academic writing, and second language acquisition.

SIMIN SATTARPOUR received her Ph.D. degree in English language teaching from Tabriz University, Iran. She has been teaching EGP and EAP courses since 2010. Her research interests include second language acquisition, task-based language teaching, corrective feedback, teaching and learning ESP and EAP, and curriculum development. 